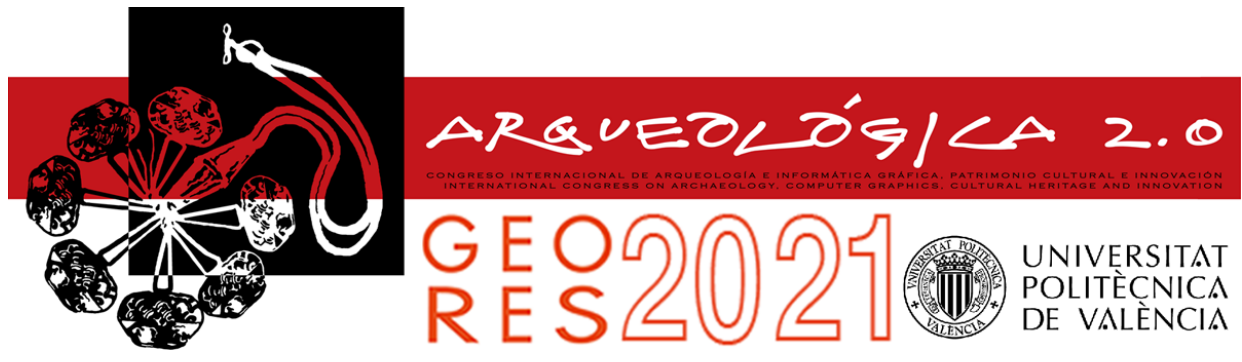

Proceedings of the joint international event $9^{\text {th }}$ ARQUEOLÓGICA

$2.0 \& 3^{\text {rd }}$ GEORES

Valencia (Spain).

26-28 April 2021

Received: 05/12/2020

Accepted: 01/04/2021

DOI: https://doi.org/10.4995/Arqueologica9.2021.12165

\title{
CARE OF ANCIENT HUMAN REMAINS. CONSERVATION AND MANAGEMENT WITH 3D MODELING AND DBMS
}

\author{
Elena Dellù*, Angela Sciatti \\ Physical Anthropology Laboratory, Superintendence of Archaeology, Fine Arts and Landscape for the metropolitan city of Bari, Strada \\ Lamberti 1, Bari 70122, Italy. elena.dellu@beniculturali.it; angelasciatti6@gmail.com
}

\begin{abstract}
:
The interaction between humanities and scientific disciplines is a slow and recent process, which is still standing influencing more and more frequently the reconstruction of our history. Ancient human remains are a significant part of our heritage, both from a cultural and biological point of view. They keep track of our evolution at a macroscopic and genetic level; for this reason, they must be adequately protected. Since 2018, the Superintendence of Archaeology, Fine Arts and Landscape for the metropolitan city of Bari (Ministry of Culture of Italy) has launched a specific protocol for the management of physical anthropological finds, with the aim of protecting, knowing and enhancing them. The use of new technologies, such as 3D modelling of the finds and the management of all archaeological and anthropological data through DBMS, will allow us to carry out long-term protection. This will be the basis for achieving new studies and enhancement activities on ancient human remains, without increasing their degradation.
\end{abstract}

Keywords: cultural heritage, physical anthropology, ethic, digital anthropology, 3D reconstruction, DBMS

\section{Introduction}

Over the last two centuries, the archaeological and speleological investigations carried out in Apulia, in southern Italy, have documented an exceptional quantity of human remains.

The Physical Anthropology Laboratory of the Superintendence of Archaeology, Fine Arts and Landscape for the metropolitan city of Bari deals with the protection and knowledge of this territorial sector. Here are preserved biological testimonies among the most significant in the world, such as Homo Neanderthalensis of Altamura, the oldest and most complete Neanderthal still known in the world (Di Vincenzo et. al., 2019; Lari et. al., 2015) (Fig. 1).

The sites with the discovery of human remains are more than a hundred; these attest to a frequentation starting from the Middle Palaeolithic. Numerous individuals have been identified - still being defined thanks to the ongoing project - which are chronologically framed between the most ancient ages, up to the most recent ones: Neolithic, Eneolithic, Bronze Age, Classical-Hellenistic period, Roman and Middle Ages.

The protection and knowledge activities launched by the Laboratory - starting from 2018 - aim to better and ethically manage human remains, as unique and unrepeatable evidence of our biological history. The goal is to:
- Define the total number of individual differentiated by chronological age / epoch;

- Reconstruct the biological profile of each individual;

- Monitor the state of decay and stabilize it;

- Implement long-term conservation procedures;

- Produce 3D models for better management, conservation, knowledge, enhancement and training purposes;

- Create a DBMS useful for the overall and multivariate management of the various information.

\section{State of art for Physical Anthropological Heritage in Italy}

Anthropological and Paleoanthropological findings are important biological evidence of pre-protohistoric and historical populations. They constitute a little known part of the cultural heritage and are protected by Italian law through the Code of Cultural Heritage and Landscape (D.Lgs. 42/2004) and the Mortuary Police Regulations (D.P.R. 285/90). Human remains preserve the biological and social history of the individuals to which they are related, both at macroscopic, microscopic and genetic levels. They constitute unique and unrepeatable osteobiographies that allow us to reconstruct the

`Corresponding Author: Elena Dellù, elena.dellu@beniculturali.it 
evolution of our species in its morphological, genetic and social components.

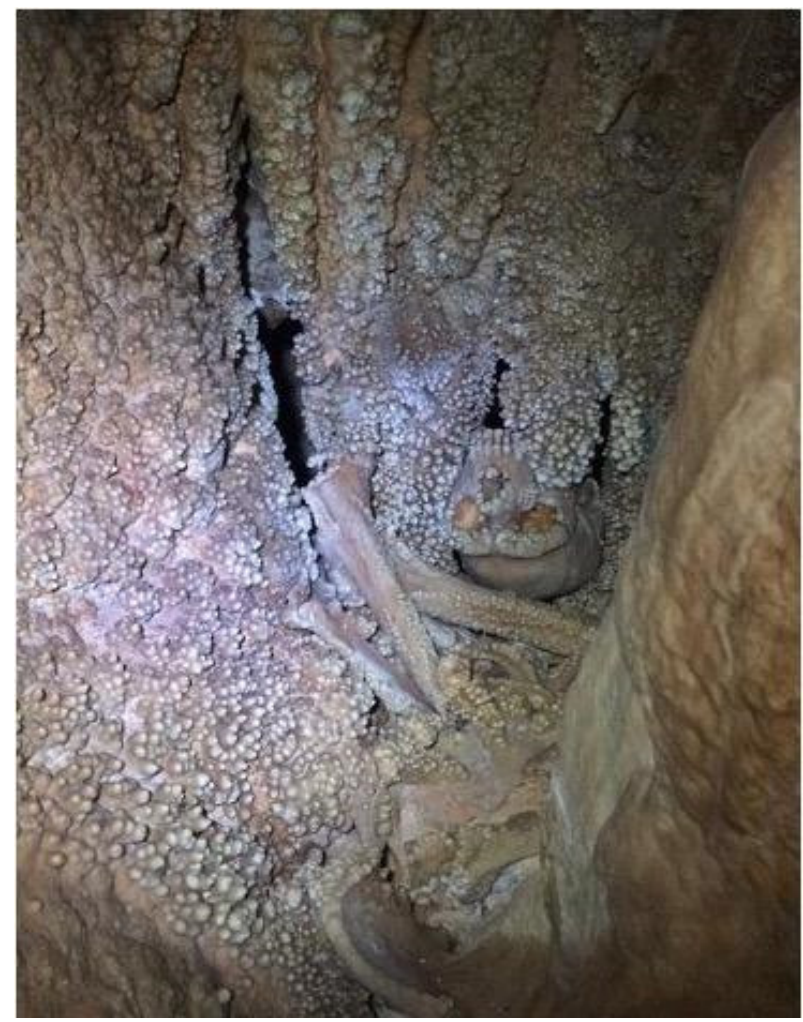

Figure 1: Altamura (BARI), Cave of Lamalunga. Homo Neanderthalensis.

For too long the informative potential of these remains has not been fully expressed, due to the marginalization and discrimination of anthropological data. Consequently, a gap was created in the methodological approach: the contribution of scientific disciplines was considered an appendix to the interpretative reconstruction of the sociocultural processes of past eras, produced almost exclusively by theoretical elaborations by the humanities sector (Perry, 2007; Earle, 2008; Knüsel, 2010; Šlaus, Petaros \& Adamić, 2015; Larsen, 2017; Dellù, 2020). This has generated a reversal of priorities and perspectives, whereby the investigation starts from the products of human actions excluding (in part or in whole) bodies of the people, who instead record first and 'into the bones' personal and social history of their time (Goldstein, 1976; Larson, 1971; Peebles, 1971; Saxe, 1970; Tainter, 1978; Rothschild, 1975; Ubelaker \& Guttenplan Grant, 1989).

In addition to archaeological research, colonial dominations, ethnographic missions and the medicallegal field have allowed the establishment of anthropological collections. Especially in recent decades, the management of human remains is leading to the emergence of ethical problems, at an international and national level.

This part of cultural heritage is defined as "sensitive materials", as explained in the ICOM Code of Ethics for Museums (art. 2.5): "collections of human remains or objects that have a sacred meaning must be acquired only if they can be placed in a safe place and treated with respect. This must be done in accordance with professional standards and with the beliefs and interests, if known, of the members of the communities, ethnic or religious groups from which the objects come".

\section{Ethics of human remains management}

Since these are testimonies of individuals who have actually lived and assumed that, over time, their identity has taken on a different value for the various communities (Ubelaker \& Guttenplan Grant, 1989), Physical Anthropological Heritages are to be considered "sensitive materials" precisely in relation to the different perception of their physical component and at the same time symbolic aspect.

In Italy this sensitivity and awareness is hardly emerging (ICOM Code of Ethics for Museums, 2009; Monza, 2014), while in the Anglo-Saxon world the issue is much more debated; all this because of the recriminations expressed by ethnic or religious communities who have seen themselves deprived of a sensitive part of their past and of the sacred and cultural sphere of their heritage (Mc Gowan \& LaRoche, 1996; Turner, 2005; Turner, Wagner \& Cabana, 2017; Ubelaker \& Guttenplan Grant, 1989).

In this case, the concept of "Cultural Heritage" is fundamental, as it goes to protect a type of finds that has contributed to the construction of the collective memory of a community, with whom it is necessary to establish a dignified and respectful dialogue of its customs and beliefs.

In the past, due to the requisitions carried out by colonial dominations and ethnographic missions, even archaeological research has not been well accepted by the "expropriated" communities. These were judged as acts of racism and violation of the sacred sites, where the remains of their ancestors are deposited; for these reasons, repatriation was requested (Ubelaker \& Guttenplan Grant, 1989; White \& Falkens, 2005, pp. 25 28; Documento sulla questione della richiesta, 2011; Monza, 2014; Monza, 2015; Turner, 2005; Turner, Wagner \& Cabana, 2017)

For example, the strong pressure carried out by Native Americans in the 1990s led to the approval, by President Bush, of the Public Law 101-601, Native American Graves Protection and Repatriation Act (NAGPRA): a protocol for laboratories and museums that provided for the return of the deceased (Mc Gowan \& LaRoche, 1996; Rose, Green \& Green, 1996; White \& Falkens, 2005; Documento sulla questione della richiesta, 2011; Turner, Wagner \& Cabana, 2017). All this did not take into account the conservation issues that would have compromised the physicochemical nature of the finds and actually caused an impoverishment of biological and physical anthropological collections worldwide.

Recently in Italy, this problem is starting to be addressed, as emerges from conferences such as Human Remains. Ethics, conservation, Display (Naples-Pompeii 20-21 May 2019, Turin 30 September-1 October 2019) carried out by the Archaeological Park of Pompei and the Egyptian Museum of Turin; Eticamente sapiens. Dallo scavo alla valorizzazione dei resti umani / Ethically Sapiens. From excavation to the enhancement of human remains (Bari, 17-18 June 2020) by the Superintendence ABAP for the metropolitan city of Bari and the University of Bari; Etica e resti umani. Linee guida e codici etici tra ricerca, documentazione, protezione e valorizzazione / Ethics and 
human remains in the archaeological field. Guidelines and ethical codes between research, documentation, protection and enhancement (Webinar, 10-11 November 2020) by CNR Ethics.

\section{Material and methods}

Starting from October 2018, the Superintendence of Archaeology, Fine Arts and Landscape for the metropolitan city of Bari has been equipped with personnel adequately trained in the physical anthropological field.

This made it possible to start a project entirely dedicated to the management of ancient human remains of the aforementioned territorial sector, also benefiting from the collaboration of trainees and anthropologists / archaeoanthropologists / bioarchaeologists operating on the regional territory and more generally in a national/international context (Fig. 2).

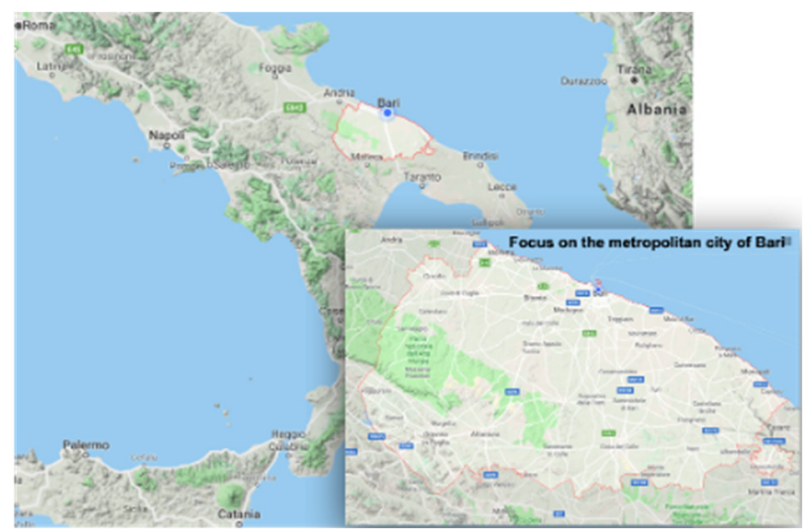

Figure 2: General and particular view of the territorial boundaries of the metropolitan city of Bari.

From a first survey carried out in the deposits of the structure and at the same time the vision of the archive or published documentation, it was possible to arrange a first screening of the archaeological and paleontological sites in which anthropological remains have been identified over the past two centuries. This was the basis on which to set up a multi-year work of managing a type of complex and sensitive cultural heritage.

The human remains available come from different environmental contexts: from karst areas overlooking the coast, to multi-layered urban areas, to hilly complexes of the Alta Murgia Barese. For these reasons, the soils in which the bones have been deposited for millennia were of a different nature and produced diversified diagenetic and taphonomic processes (Canci \& Minozzi, 2015; Duday, 2006; White \& Falkens, 2005). In some cases, they represent isolated testimonies of depositional practices, but in the majority, they constitute funerary areas with tens to a few hundred graves.

It was therefore decided to start a systematic study on two chronological periods, for which a greater number of information was available, such as individuals of the Neolithic age and those of the Middle Ages (Fig. 3). In both cases, there were good conditions of conservation and cleanliness, ease of retrieval in the deposits, preliminary cataloguing of biological profiles, archaeological studies of the contexts and relative dating (often also obtained through ${ }^{14} \mathrm{C}$ analyzes) and, for the most recent investigations, also 3D modelling carried out during excavation.

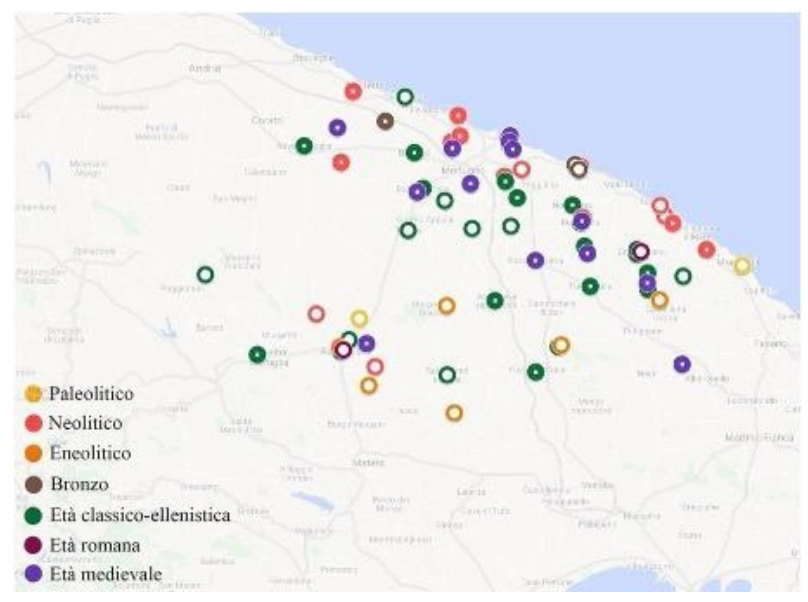

Figure 3: Metropolitan city of Bari. Distribution of archaeological and paleontological sites with the discovery of human remains.

\section{Data acquisition}

\subsection{Archaeological Data}

The archaeological contexts data were identified through a composite research that initially involved the paper and digital archives of the Superintendency. In this way, extrapolated data were available from excavation reports, from stratigraphic unit cards, from topographic surveys and from 3D models obtained through Close Range Photogrammetry (Thanaphattarapornchai, 2012).

This was following by the use of complex cataloguing system with web-based use, designed and continuously implemented by the ICCD-MiC (Central Institute for Catalogue and Documentation), such as the SIGECweb (General Information System of the Catalogue) (www.sigecweb.beniculturali.it). This manages the entire project of Italian Cultural Heritage cataloguing, the production and dissemination of cataloguing standards, in addition to the assignment of the unique catalogue codes and the online publication of the catalogue cards for users. For this reason it was possible to have data referable to many archaeological excavations inherent to the project.

\subsection{Anthropological data and scientific analyses}

Similarly to what was done for the recovery of archaeological data, also for anthropological materials the first step was to identify the existing documentation relating to the human remains in question. Therefore, study reports, Depositional Stratigraphic Unit Cards, AT Cards of Anthropological Findings, reports of scientific analyses and diagnostic investigations $\left({ }^{14} \mathrm{C}\right.$, aDNA, isotope analyses, microscopy analyses, confocal microscopy analyses, X-rays, CT scans, etc.) were identified.

The Lab is also carrying out new targeted studies on each individual based on standard and experimental anthropological methods used in science (Canci \& Minozzi, 2015; White \& Falkens, 2005). The aim is to define the state of conservation and the completely biological profile (sex, age, height, pathologies, 
biomechanical stress, etc.). Since archaeological excavations are destructive activities and at the same time human remains easily degradable and fragmentable, it was decided to integrate data from the previous documentation with the new acquisitions. Given the absence of normalized biological profile cards by $\mathrm{MiC}$, a new complex data storage prototype has been created, based on excel worksheets for use by the Lab and which is extending over the entire Apulian territory. This became fundamental to have a system of standards, where cataloguing tools and rules were based on homogeneous criteria to be used in contexts referable to an extended territory and to different chronological arcs (Fig. 4).

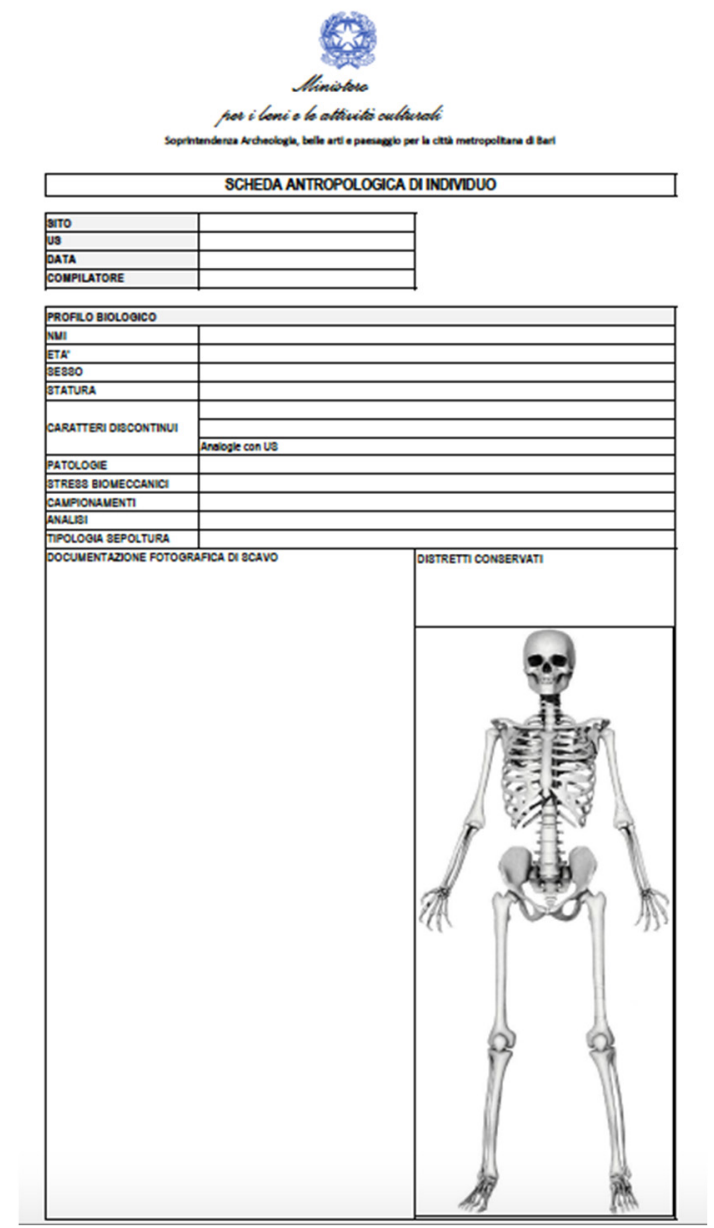

Figure 4: Superintendence of Archaeology, Fine Arts and Landscape for the metropolitan city of Bari, Physical Anthropological Laboratory. First pages of the new normalized anthropological profile cards.

Hand in hand with what has been inserted more extensively on the biological profile sheets of each individual, the AT (Anthropological Finds) and MINP (Asset Value Inventory Form) catalogue sheets are being placed on SIGECweb so that all data are available to the community.

\subsection{Conservative incoming monitoring}

The anthropological finds submitted to the protection of the Lab come from different environmental and chronological contexts. Most of them are located in the deposits of the Superintendency, but in some limited cases they are still preserved in the place of discovery, like the Homo Neanderthalensis of Altamura (Di Vincenzo et. al., 2019; Lari et. al., 2015) (Figs. 5 and 6).

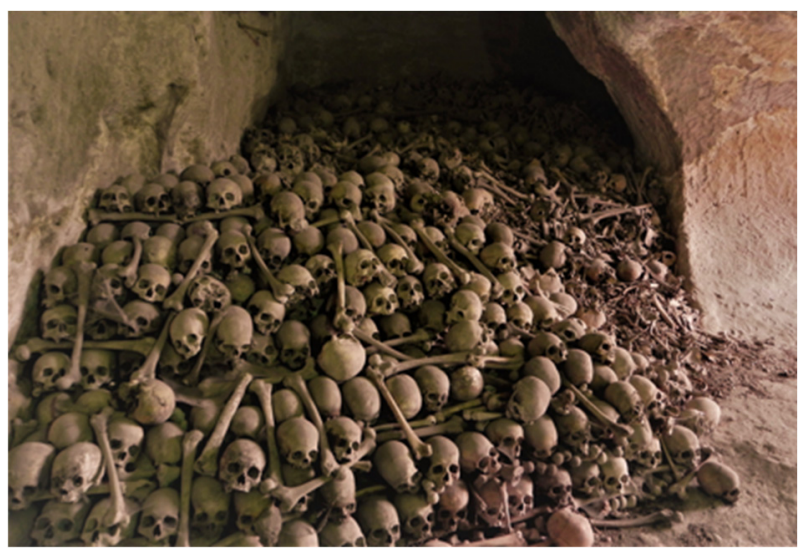

Figure 5: Rock Church of Saint Michael, Gravina in Puglia (Metropolitan city of Bari). Particular conditions of identification and current position of skeletonized human remains.

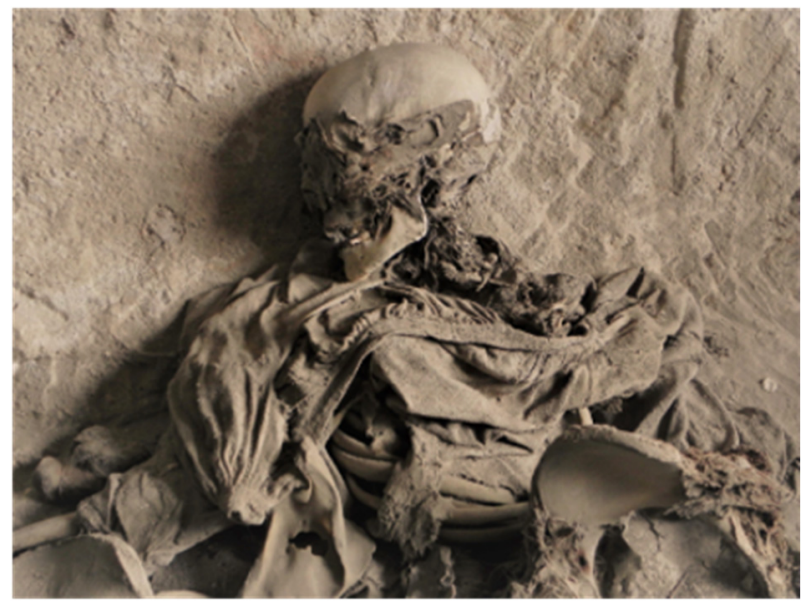

Figure 6: Rock Church of Saint Michael, Gravina in Puglia (Metropolitan city of Bari). Particular conditions of identification and current position of mummified human remains.

There are different diagenetic and taphonomic conditions to which human remains have been subjected over the millennia. At the same time, the moment of their discovery led to changes in the chemical-physical stability that they had reached during the laying (Cassman, Odegaard \& Powell, 2006; Beaubien, 2019; Freiwald \& Miller Wolf K. A., 2019). For these reasons, from the moment of their identification and subsequent extraction by archaeologists and anthropologists, the finds have undergone new changes depending on the new conditions.

At present in Italy there are no monitoring and conservation procedures entirely dedicated and tested on human remains, with the exception of mummified individuals (Samadelli, Zink, Roselli, Gabrielli, Tabandeh \& Fernicola, 2019). For this reason, a new model of conservation data sheet was drafted at the Lab, formulated on the basis of the emergency data sheets prepared by the MiC-Central Institute for Restoration in the context of the management of artworks from the areas affected by the earthquake of L'Aquila in 2009 and Emilia Romagna in 2012 (http://www.icr. beniculturali.it/pagina.cfm?usz=5\&uid=47 3). 
The datasheet was designed to carry out the initial and incoming/long-term monitoring of human remains at the $\mathrm{Lab}$, in order to normalize the information of each find (Fig. 7).

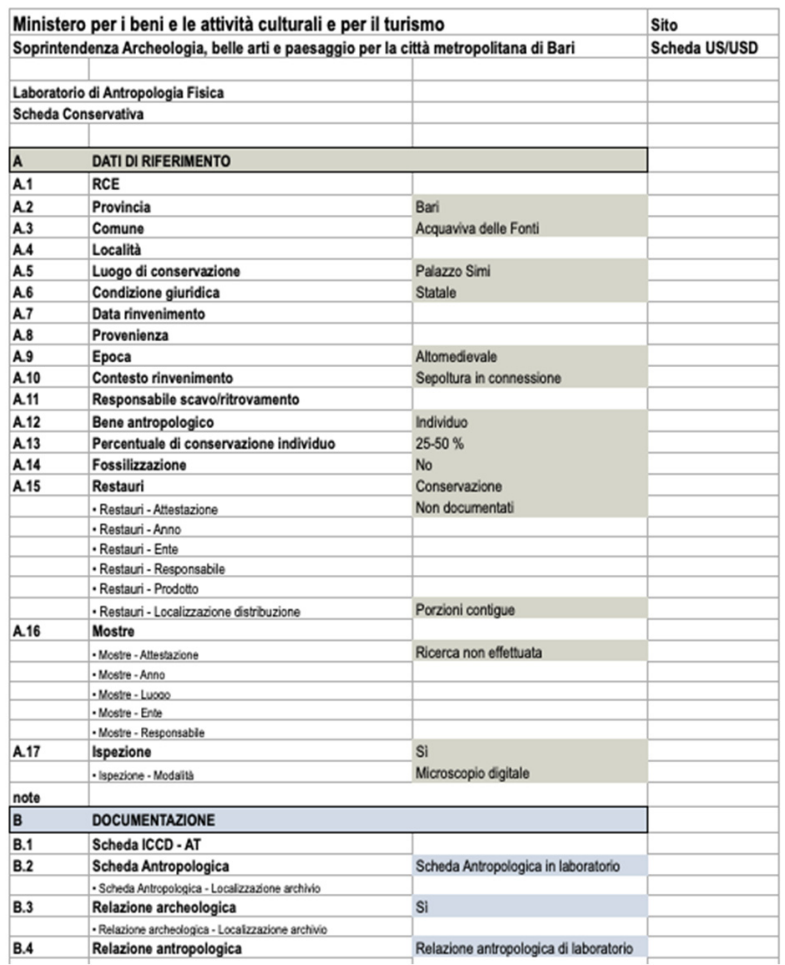

Figure 7: Superintendence of Archaeology, Fine Arts and Landscape for the metropolitan city of Bari, Physical Anthropological Laboratory. First pages of the new normalized Anthropological Conservation Data Sheet.

This was created with excel worksheets and can then be inserted into the DBMS. The structure includes fields with closed answers, in order to normalize the information as much as possible, and is divided into three sections:

- Reference data of the find (place and date of discovery; place of current conservation; epoch; percentage of conservation of the individual; fossilization processes; restorations; samplings; scientific analyses; exhibitions; inspections; etc.) (Fig. 8);

- Documentation (AT sheet; technical sheet of the biological profile; photographic documentation; 2D and 3D graphic documentation; bibliography; etc.);

- Current location conditions (air conditioning, exposure to heat sources, type of container; risks from exposure, mould, humidity, vibrations; safety; etc.) (Fig. 9);

- Technical data and state of conservation (quantitative and qualitative degree of preservation of the individual; degree of compactness of lamellar bone; taphonomicdiagenetic deformations; decohesion; friability; fracturing; chromatic variations; concretions; demineralization; etc.).

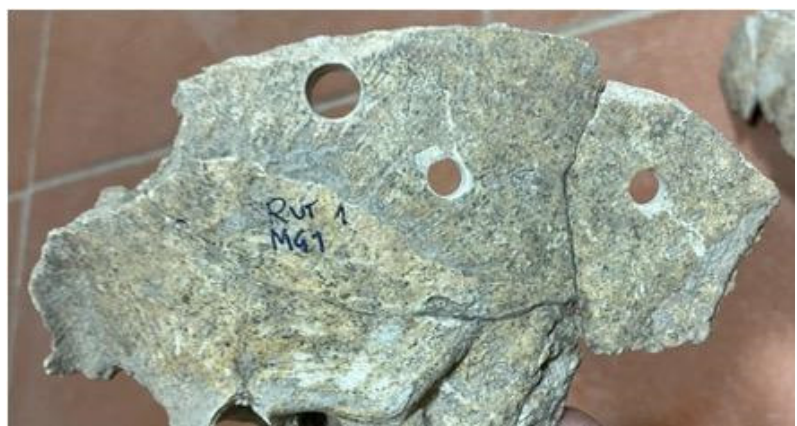

Figure 8: Superintendence of Archaeology, Fine Arts and Landscape for the metropolitan city of Bari, Physical Anthropological Laboratory. Parietal bone of a Neolithic individual with numerous traces of sampling for scientific analysis.

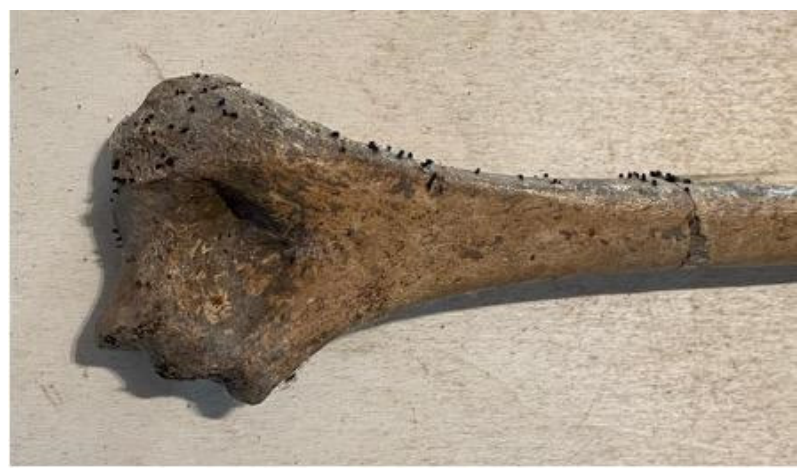

Figure 9: Superintendence of Archaeology, Fine Arts and Landscape for the metropolitan city of Bari, Physical Anthropological Laboratory. Humerus of a Neolithic individual with proliferation of insects.

\subsection{D modelling}

In order to ensure the long-term conservation of ancient human remains, the Lab has launched digital procedures through tridimensional modelling of anthropological finds.

These new technologies allow to conduct a digital anthropological and anthropometric study (Brzobohatá, Prokop, Horák, Jančárek \& Velemínská, 2012; Di Vincenzo, Profico, Tafuri \& Manzi, 2016; Robedizo, 2016; Petarosa et al 2017; Rmoutilová et al, 2018; Wrobel, Biggs \& Hair, 2019); at the same time, they are useful for educational purposes (Serrano, Jiménez Arenas \& Esquivel, 2016). Only recently researchers have begun to utilize 3D digital data to quantitatively evaluate sexual skeletal traits, reducing errors and simplifying statistical analysis for a variety of fields of study, such as clinical, biomedical, forensic, biological and anthropological ones. The latter, in fact, can be carried out correctly: for example, several studies compared the measurements on bones elaborated from digital techniques to real bones. The result was that the virtual models are highly accurate (Decker, Ford, Hoegstrom \& Hilbelink, 2008).

Moreover, supported by computer tomography (CT) scans, 3D output allows to have accurate acquisition data about human bones, that can be also useful to a palaeopathological research (Stull, Tise, Ali \& Fowler, 2014; Urbanová, Hejna \& Jurda, 2015). In fact, the application of CT scan allows for better contrast resolution that results in more detailed images of bones and offers a rapid processing time. 
From a conservative point of view, 3D modelling is aimed to preserve real skeletal remains: it allows a digital study of them that does not require manipulation, without compromising the physical and chemical nature of the material. Then it also preserves numerically constrained fragile skeletal and dental material in paleoanthropological collections (Fiorenza et al., 2018).

For these reasons, the Lab has launched a digitization plan of archaeological and anthropological heritage, under its own protection. Close-range photogrammetry (Thanaphattarapornchai, 2012) - and also Laser Scanning (Karadimas, Kotsopoulos, Papastamatiou, Spyropoulos \&Tsergoulas, 2010) - are useful tools from the excavation phase yet. They provide accurate digital surface models and photo-realistic outputs, optimizing time, for example during operations of preventive archaeology. They also allow to collect information in detail compared to traditional techniques of graphic documentation, so in retrospect, it is possible to review and understand information collected also by those who were not physically on the field.

Thanks to the economy and functionality of the method, through a well-studied photogrammetric survey it is possible to collect materials for elaboration of a 3D model referred to an object or a whole archaeological context.

So ancient human remains collected by Superintendence have undergone the following operations: once placed the object of interest on support, many photos have been taken at $360^{\circ}$ under monitored light conditions (Fig. 10). Then the frames captured in sequence were uploaded to specific software (such as Agisoft Photoscan and Metashape Professional). After aligning points, we have been able to build a dense cloud and a mesh and so elaborate an output which errors were fixed postproduction. The final digital output has been a 3D mesh, known as a polygonal model, representing the morphology of the scanned object. The texture has given the virtual model a realistic appearance with colour and other optical qualities (Kotulanová, Chalás \& Urbanová, 2014). Finally, according to the needs, the file has been exported in various formats.

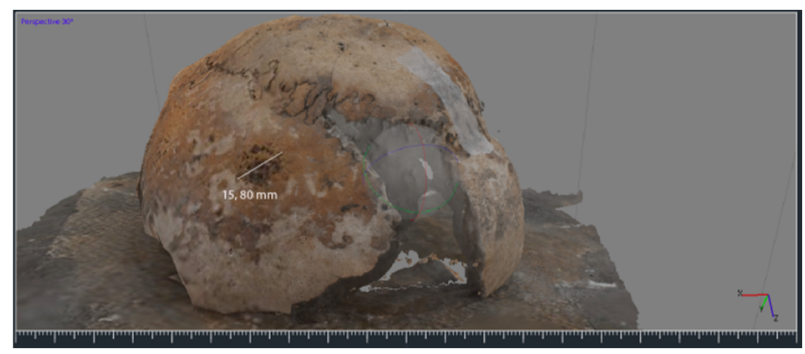

Figure 10: Superintendence of Archaeology, Fine Arts and Landscape for the metropolitan city of Bari, Physical Anthropological Laboratory. 3D model of a medieval skull characterized by pathological circular lesions (metastatic carcinoma vs. multiple myeloma). Method: Photogrammetry; software Agisoft Photoscan, author A. Sciatti.

For the purposes of suitable anthropological documentation, aimed at the morphological, morphometric, palaeopathological and biomechanical study of individual bone remains, there was a need for the calibration of the photographic instrumentation with high resolution, that is, able to guarantee a high accuracy of the anatomical details. At the same time, in the phase of elaboration of the polygonal/three-dimensional model (Reverse Modeling) particular attention was paid to the editing phase (Chibunichev, Knyaz, Zhuravlev \& Kurkov, 2018; Seguchi \& Dudzik 2019). This is because software or non-specialized operators in the anthropological field could correct the various geometries by adopting parameters connected with the aesthetic rendering of the 3D product, effectively homogenizing the surfaces, decimating the meshes and closing the gaps. All this can compromise a correct reading of the finding and lead to an incorrect interpretation of the data.

3D models will prove particularly useful for recreating the original volumes of the bodies of the deceased. On them, it will be possible to rework - through post-processing phases - the biomasses (formulated on the basis of anthropological studies) that have degraded during the course of post-mortem taphonomic events (Cabo, Dirkmaat, Adovasio \& Rozas, 2012).

At the same time products are useful for the learning of students of all levels; useful, in this perspective, is the virtual collection edited by the Smithsonian Institution's Human Evolution Center, in Washington D.C., which has created an extensive online database of primate and hominin fossils available for viewing online and free of charge (https://humanorigins.si.edu/evidence/3dcollection).

In this way, new virtual exhibitions will be able to take advantage of $3 \mathrm{D}$ models to be shown in multimedia products (Barceló, 2000); at the same time, these could be used for new accessibility plans with the adoption of tactile sensory experiences through 3D prints (EvelynWright, Dickinson \& Zakrewski, 2020).

3D modelling results in a functional and sensible tool that softens visitors' effects and creates new approaches to customer experience, for example through augmented reality (Barceló, 2000). It is also useful for scientific needs, as demonstrated by AR experience offered by Field Museum of Chicago which reproduces a funerary context that can be looked through in order to understand archaeological steps of mummy deposition.

Ultimately, from a 3D model, it is possible to operate a face reconstruction of an individual that, if it is well-made (Lee, Yoon, Song, Wilkinson \& Shin 2014; Suppersberger Hamre, Ersland, Daux, Parson \& Wilkinson, 2017) can be an educational tool of enhancement for visitors and so an important instrument of public archaeology (Allen, 2014).

\section{Results}

\subsection{Database Management System}

The aim of Physical Anthropology Laboratory by Superintendence of Archaeology, Fine Arts and Landscape for the metropolitan city of Bari is to promote not only physical and chemical conservation, but also digital one for the consistent anthropological heritage under its own protection. This by virtue of the particular nature of anthropological finds that, in comparison to others, is composed of biological material and so it is at higher conservative risk. At the same time, a digital approach is aimed to support a circular, free and democratic sharing of current knowledge. 
Ethical, sociocultural and emotional implications related to sharing information or images about ancient human remains, and generally, the archaeology of the dead, are sometimes a restriction on scientific research (Manacorda, 2014; Volpe, 2019).

However human remains are not objects to study on the verge of reification, but subjects with their own dignity and they must be managed in a dualistic perspective between ethical and professional deontology (Colleter, 2019). So, this sensible approach is necessary to ensure respectful management of biological evidence that effectively belongs to our cultural heritage.

Due to the digital revolution, the acquisition of archaeological data has changed more than before. The digitization of information has allowed a faster, more efficient and standardized data recording, that facilitates the synthesis work required by the discipline.

In order to encourage the use of advanced technological procedures that are effective, efficient, ergonomic and open-source, testing for the establishment of a preliminary Database Management System is taking place at Physical Anthropology Lab. The main purpose is to allow to store, save, edit, sort and query information about the knowledge of physical anthropological heritage (Nagar, 2011) and so to create an open data and opensource system (Cook, 2018) for a "public bioarchaeology" that is sustainable, stimulating, free and democratic (McGimsey, 1972; Skeates, McDavid \& Carman, 2012; Bonacchi, 2014; Moshenska, 2017; Valenti, 2017; Volpe, 2020).

The requirement is shown for a large amount of material surveyed. Therefore, to ensure consistency of work and an easier finding of information, it was necessary to suggest systematic procedures for data storage, from the acquisition on archaeological sites. This approach will optimise the recording of human bones from the context of finding yet and it configures as a management tool able to manage large quantities of human skeletal remains, count and locate them.

In this way we focus on the elaboration of a real mapping of physical anthropology collection finding in the area of metropolitan city of Bari: so the digitization should interact also in GIS software (Ruda, 2016), considering the List of Apulian Cultural Heritage (CartAPULIA, Progetto finanziato dal P.O. 2007-2013 - Linea 4.2).

At a preliminary step, data collection starts from the information currently known and inserted in the SigecWeb cataloguing system of the Ministry of Culture; therefore a revision of previous documentation is a prerequisite.

Such operations require a rather elaborate time of analysis and design of the structure that will be configured as a real repository (Polly \& Stringer, 2011).

Already from the beginning, it is necessary to define the degree of analyticity to record information within the DB (Valenti, 1998; Fronza, 2001).

Normalizing language is indispensable to give synthetic and direct information, to homogenize incoming data in order to ensure sustainability in terms of costs and time, not sacrificing archaeological and anthropological research
At present, the implementation of such systems is offered by various software, as Microsoft Access 2013, created for the management of relational databases (RDBMS) that exploits the Microsoft Jet Database Engine and which integrates with itself a module for rapid application development (Rapid Application Development). The saving structure follows the relational table model, which allows storage and manages data in tables composed of a large number of records. Each one contains data separated by fields and it is possible to create direct relationships between records.

Because it is a work still in progress, testing of different solutions is legitimate: so we can identify the one that best suits our needs. The purpose is to design an open and implementable DBMS, including not only archaeological information (on the model of ICCD classification), anthropological data (as results from laboratory analysis) and conservative one, but also interacting with other sources, for example as historical ones, with a section of literature in order to ensure a bioinformatics reconstruction as complete as possible (Nielsen, Paul, Albrechtsen \& Song Y. S., 2011; Korneliussen, Albrechtsen \& Nielsen 2014; Ehler, Novotńy, Juras, Chylénski, Moravčík, \& Pačes, 2019).

Moreover, for this purpose, it is necessary to include photographic and eventually 3D documentation, which computer weight may compromise DBMS efficiency. To avoid the problem, the use of QR code seems efficient: users are directed to the web link of the 3D model, as it is possible with Sketchfab platform (Zechini, Holmstrom, Voas \& Killgrove, 2016).

For the aims pursued by the Laboratory, the use of opensource software HumanOs has proved very useful (Colletter, Romain \& Barreau, 2020): it is a practical tool for archaeologists and anthropologists for data acquisition in an ergonomic and sustainable way, open-source and without internet connection.

Skeleton is a key element of DBMS, accompanied by localization and context references and archaeological, taphonomic, conservative, anthropological and biological information.

Some features could be improved, such as the possibility to insert excavation and lab images or to create $3 \mathrm{D}$ models useful for educational and scientific purposes.

So digital recording allows real-time processing of one or more samples, its comparison between different contexts and reduces the occurrence of errors for incoming data.

\subsection{Conservative long-term monitoring}

With "preventive conservation" we identify «all measures and actions aimed at avoiding and minimizing future deterioration or loss. They are carried out within the context or on the surroundings of an item, but more often a group of items, whatever their age and condition. These measures and actions are indirect - they do not interfere with the materials and structures of the items. They do not modify their appearance» (ICOM Terminology to characterize the conservation of tangible cultural heritage, 2010).

In Italy, the idea of "preventive conservation" is closely related to the monitoring of archaeological and artistic assets in museum spaces or for exhibition (Giannini, 
2010; Bonvicini, 2010). But guidelines on the conservation of anthropological heritage are hardly defined.

As already shown by conservative incoming monitoring, Physical Anthropology Laboratory is trying to adopt a management and conservation protocol also with longterm monitoring, in order to minimise the damage caused by the inevitable degradation of organic material (Michalski \& Pedersoli, 2016) (Fig. 11).

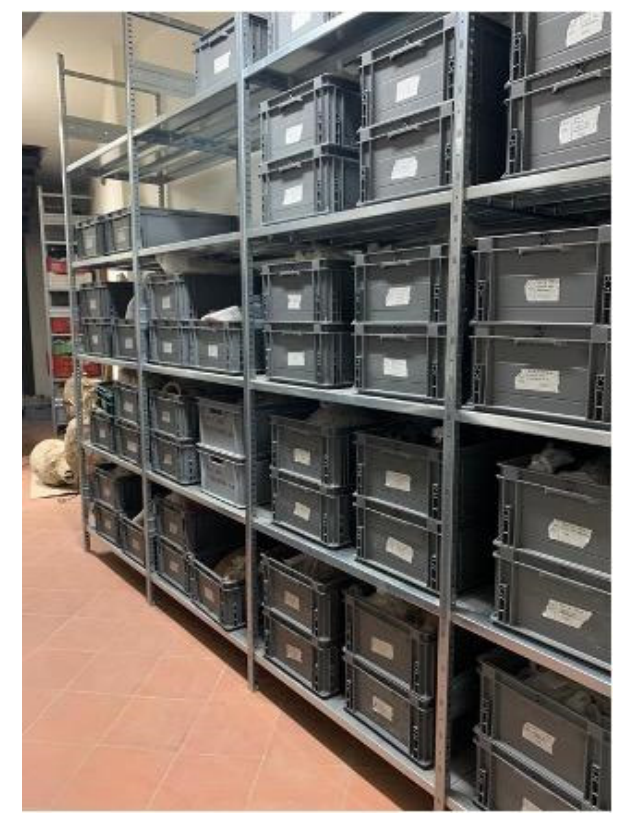

Figure 11: Superintendence of Archaeology, Fine Arts and Landscape for the metropolitan city of Bari. New staging of the archaeological and anthropological deposits of the structure of Palazzo Simi.

So in conjunction with the first attempts on national territory (ch. 3), Lab is moving on the model of Emergency cards in use at the MiC-Central Institute for Restoration (http://www.icr.beniculturali.it/).

These measures are intended to ensure the integrity and identity of anthropological remains over time (Pedersoli, Altomarchi \& Michalski, 2016) and they can be summarised in: conservation, handling, emergency and legislative plan, microclimatic and environmental monitoring (light, humidity, contamination and proliferation of mould and parasites), storage regulation (Marquardt, Montet-White \& Scholtz 1982), use of inert material for housing remains (Cassman \& Odegaard, 2004), staff training, collaboration with other specialists, relationships with potential stakeholders, best practices for public education.

In summary, the Lab is promoting action of deposits adjustment and storage conditions ensuring an entomological control (Matè, Adamo, Cotellessa, De Francesco \& Trematerra, 2016), monitoring spaces, packaging and assessing over time probable changes in the conservation state of anthropological remains (Matè \& Palazzi, 2017).

\subsection{Fruition and enhancement}

As declared by the Convention on the Value of Cultural Heritage for Society, «rights relating to cultural heritage are inherent in the right to participate in cultural life, as defined in the Universal Declaration of Human Rights» (art. 1a, Faro Convention, 2005) and «the conservation of cultural heritage and its sustainable use have human development and quality of life as their goal» (art. 1c, Faro Convention, 2005). If we consider that «a heritage community [...] wish, within the framework of public action, to sustain and transmit [cultural heritage] to future generations» (art. 2b, Faro Convention, 2005), it is clear that these principles can be implemented only through innovative forms of preservation and enhancement.

But in practice, it is not always that easy. Because of wrong conservative conditions and carelessness due to lack of human and economic resources, cultural heritage, and especially ancient human remains, goes toward a progressive deterioration of physical and chemical conditions; so its knowledge is in danger for future generations.

Therefore, modern technologies such as photogrammetry, 3D modelling and printing are necessarily useful to ensure suitable conservation and at the same time enhancement and training purposes. In this way, real ancient human remains are not affected and they are handled as little as possible. So there is a new way to satisfy the needs of scientific research and to ensure an educational and respectful tool that replaces real skeletal remains (Petarosa et al 2017).

This aspect is important also for the communication of Bioarchaeology: because of the nature of this sensible cultural heritage, it is necessary to consider the different impact that his view can generate and the segmentary of the public.

The choice of displaying ancient human remains is not insignificant (Redfern \& Bekvalac, 2013) because, just as in the past, it represents an intimate and symbolic moment for the visitor, which directly seems not to belong to the same community of the deceased, but it really offers a cathartic experience that the sight of skeletal remains produces. The elaboration of death is a human stage with ancestral roots: therefore the museum exhibition takes on not only a didactic value, but also an intimate meaning, depending on viewer sensibility. Hence the doubts about the museum choice of displaying or not the infant skeletal remains.

The potential offered by modern technologies is still unexplored. For example, never as today because of the crisis situation due to the Covid pandemic, we have tested the impossibility to reclaim our rights relating to cultural heritage. Only through virtual experience with social platforms, we have compensated for this human and cultural deprivation, shortening the physical distance and discovering new ways of interaction.

At the same time, this situation brought out the socioeconomic gap that kept many people from the fruition of cultural heritage.

In the first phase, many museums and institutions dealing with cultural heritage have produced an excessive quantity of digital products proposed on social platforms (Mandarano, 2019), almost like a desperate scream by the culture that claims its place in the world and human beings' lives.

But, as Umberto Eco said, «we risk being overwhelmed by an excess of information, and the difference between 
silence and too much noise is really minimal». We must not forget that the progress of knowledge needs a real human identity and the virtual experience shall be designed as an auxiliary tool, and not as a substitute one.

In that sense, the Physical Anthropology Laboratory has reflected on best practices for anthropological remains enhancement in many ways.

From a scientific point of view, it has encouraged archaeoanthropological research publishing and a preliminary elaboration of visual tridimensional content that will be inserted in DBMS, useful to the digital study of ancient remains.

With the aim of promoting knowledge of sensitive heritage, the Laboratory is also opened to the wider public: on these occasions, we offer an overview of archaeoanthropologists work and the potential of the study of ancient human remains (Fig. 12). At the same time, a sociological survey was launched through the drafting of a questionnaire submitted to visitors: so we can understand how they perceive visiting and seeing the experience of ancient human remains. In this way, consumers can give feedback useful to improve customer experience in terms of the museum economy and take part in a new model of sensitive education.

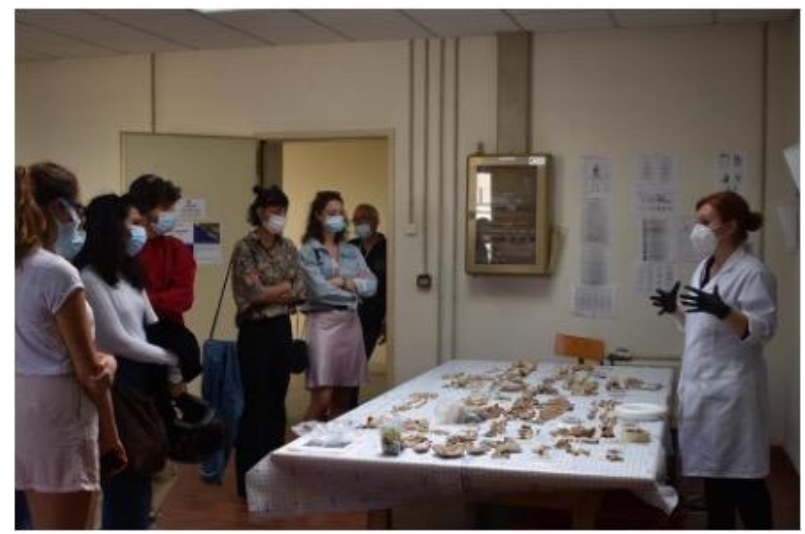

Figure 12: Superintendence of Archaeology, Fine Arts and Landscape for the metropolitan city of Bari, Physical

Anthropological Laboratory. Public communication activities carried out during the European Heritage Days 2020.

Death is a cathartic experience and the seeing of ancient human remains can arouse different feelings depending on the different degree of sensitivity. It is necessary for education and sensibilization of anthropological heritage and before that an accurate analysis of the public, not ever adequately prepared to tolerate a similar impact.

Only with this respectful approach, it is possible to present the potentiality of the study of ancient human remains also to non-experts, with which it is necessary to establish a constructive relationship in order to increase the sense of belonging to the heritage community (art. 2b, Faro Convention, 2005).
Our humble effort represents a contribution to the definition of the best practices to ensure the preservation and the knowledge of cultural heritage (Elfadaly \& Lasaponara 2019).

\section{Discussion}

If until 2018 the human remains found in the territory of the metropolitan city of Bari had not been managed at a conservative level by personnel specialized in the anthropological field, subsequently it was possible to implement a new methodological approach.

The Superintendence of Archaeology, Fine Arts and Landscape for the metropolitan city of Bari has created a new Laboratory of Physical Anthropology, the only structure of MiC for the whole Apulia, thanks to which an interdisciplinary and complex management project of ancient human remains has been launched.

The new practices involve aspects of macro-microscopic and genetic conservation, scientific knowledge, enhancement and training purposes. The management protocols aim to adopt an ethical approach that takes into consideration the respect for these 'sensitive materials' (as people), their long-term conservation and their public knowledge through new ways of dialogue.

The modern methods of 3D model and at the same time the use of DBMS (for the overall management of information) are proving extremely useful to avoid an increasing degradation of this type of biological finds, which are easily perishable. If up to now the experimentation has been taking place on anthropological assets attributable to the Neolithic and medieval age, it is hoped to extend this type of approach to all the biological collections of the Superintendence of Archeology, Fine Arts and Landscape for the metropolitan city of Bari.

\section{Acknowledgements}

Funding: This research was fully funded by the Italian Ministry of Culture.

We would like to acknowledge the numerous archaeologists, anthropologists, archaeoanthropologists, conservative restorers of MIC, MIUR and free professionals who, over the years, have worked in the territory of the metropolitan city of Bari providing useful data for the current project. In particular L. La Rocca, F. Radina, M. R. De Palo, M. Corrente, A.M. Tunzi, S. Cicala, V. Scattarella, S. Sublimi Saponetti, G. Manzi, M. Cuccovillo, P. D'Onghia, G. Panzarino, L. Lamanna, S. Sivilli.

We also acknowledge the architect M. Piccarreta, director of the Superintendence ABAP for the metropolitan city of Bari and all the staff of the institution; the professors D. Nuzzo, director of the School of specialization in archaeological heritage of Bari (University of Bari - Aldo Moro), and G. Volpe.

\section{References}

Allen, H. (2014). Handing the Past to the Present: The Impact of 3D Printing on Public Archaeology. Pennsylvania Archaeologist, 84(1), 9-13.

Beaubien, F.H. (2019). Field Conservation of Skeletal Remains: Stabilization Treatment Techniques and Implications for Future Analysis. Advances in Archaeological Practice, 7, 23-29. https://doi.org/10.1017/aap.2018.36 
Bonvicini, C. (2010). La conservazione preventiva nel contesto degli standard museali italiani, in Complesso Museale Santa Maria della Scala (Ed.) Conservazione preventiva e controllo microclimatico nel contesto degli standard museali, Siena (pp. 19-27).

Brzobohatá, H., Prokop, J., Horák, M., Jančárek, A., \& Velemínská, J. (2012). Accuracy and benefits of 3D bone surface modelling: a comparison of two methods of surface data acquisition reconstructed by laser scanning and computed tomography outputs. Collegium antropologicum, 36/3, 801-806.

Cabo, L.L., Dirkmaat, D.C., Adovasio, J.M., \& Rozas, V.C. (2012). Archaeology, mass graves, and resolving commingling issues through spatial analysis. In D. C. Dirkmaat (eds), A Companion to Forensic Anthropology, Hoboken-New Jersey, pp. 175-196. https://doi.org/10.1002/9781118255377.ch9

Canci, A., Minozzi, S. (2015). Archeologia dei resti umani. Dallo scavo al laboratorio, Roma.

Cassman, V., \& Odegaard, N. (2004). Human Remains and the Conservator's Role. Studies in Conservation, 49(4), 271282. https://doi.org/10.2307/25487703

Cassman, V., Odegaard, N., \& Powell, J. (2006), Human Remains: Guide for Museums And Academic Institutions, Lanham. https://doi.org/10.1525/aa.2007.109.3.551

Chibunichev, A., Knyaz, V., Zhuravlev, D., \& Kurkov, V. (2018). Photogrammetry for Archaeology: Collecting Pieces Together. ISPRS - International Archives of the Photogrammetry, Remote Sensing and Spatial Information Sciences. XLII-2, 235-240. https://doi.org/10.5194/isprs-archives-XLII-2-235-2018

Colleter, R. (2019). Les restes humains archéologiques en France: entre objets de science et sujets de droit. Canadian Journal of Bioethics, 2/3, 97-108. https://doi.org/10.7202/1066467ar

Colletter, R., Romain, J. B., \& Barreau, J. B. (2020). Humanos: an open source nomadic software database. Virtual Archaeology Review, 11(23), 94-105. https://doi.org/10.4995/var.2020.13422

Convention on the Value of Cultural Heritage for Society, Faro (2005).

Cook, K. (2018). Open Data as Public Archaeology: The Monumental Archive Project. Online Journal in Public Archaeology Special, 3, 177-194. http://dx.doi.org/10.23914/ap.v8i2.152

Bonacchi, C. (2014). Understanding the Public Experience in the UK and Italy: A Call for a Sociological Movement of Public Archaeology. European Journal of Post-Classical Archaeologies, 4, 377-400.

Decker, S., Ford, J., Hoegstrom, E., \& Hilbelink, D. (2008). Virtual skull Anatomy: Three-Dimensional Computer Modeling and Measurement of Human Cranial Anatomy. Proceedings of the American Academy of Forensic Sciences, 14, 312.

Decker, S. J., Davy-Jow, S. L., Ford, J. M., \& Hilbelink, D. R. (2011). Virtual Determination of Sex: Metric andNonmetric Traits of the Adult Pelvis from 3D Computed Tomography Models. Journal of Forensic Science, 56(5), 1107-1114. https://doi.org/10.1111/j.1556-4029.2011.01803.

Dellù, E. (2020). Antropologia e Archeologia. Un approccio bioculturale per la ricostruzione delle popolazioni storiche, in G. Castiglia \& Ph. Pergola (eds.), Instrumentum Domesticum. Archeologia cristiana, temi, metodologia e cultura materiale della tarda antichità e dell'alto medioevo, Città del Vaticano (pp. 233-258).

Di Vincenzo, F., Churcill, S.E, Buzi, C., Profico, A., Tafuri, M.A., Micheli, M., Caramelli, D., \& Manzi, G. (2019). Distinct among Neanderthals: The scapula of the skeleton from Altamura, Italy. Quaternary Science Reviews, 217, 76-88. https://doi.org/10.1016/j.quascirev.2018.11.023

Di Vincenzo, F., Profico, A., Tafuri, M. A., \& Manzi, G. (2016). The cranium of the Altamura Neanderthal (Puglia, Italy): virtual extraction, digital restoration and morphological notes, Poster Conference EHSE - 6th Annual Meeting (Madrid, 24-28 September 2016), 80.

Documento sulla questione della richiesta, 2011 = Documento sulla questione della richiesta, presentata dal Governo Australiano, di restituzione di resti scheletrici umani provenienti dal territorio Australiano conservati presso la Sezione di Antropologia ed Etnologia del Museo di Storia Naturale dell'Università di Firenze, Museologia Scientifica, Nuova serie, $5,11-21$.

Duday, H. (2006). Lezioni di Archeotanatologia. Archeologia funeraria e antropologia sul campo, Roma.

Earle, T. (2008). Anthropology Must Have Archaeology. Archaeological Papers of the American Anthropological association, 2008, 17-26. https://doi.org/10.1525/ap3a.2003.13.1.17

Ehler, E., Novotńy, J., Juras, A., Chylénski, M., Moravčík, O., \& Pačes, J. (2019). AmtDB: a database of ancient human mitochondrial genomes. Nucleic Acids Research, 47, D29-D32. https://doi.org/10.1093/nar/gky843; https://amtdb.org/

Elfadaly, A., \& Lasaponara, R. (2019). On the Use of Satellite Imagery and GIS Tools to Detect and Characterize the Urbanization around Heritage Sites: The Case Studies of the Catacombs of Mustafa Kamel in Alexandria, Egypt and the Aragonese Castle in Baia, Italy. Sustainability, 11, 2110, 1-18. https://doi.org/10.3390/su11072110 
Evelyn-Wright, S., Dickinson, A., \& Zakrewski, S. (2020). Getting to grips with 3D printed bones: Using 3D models as 'diagrams' to improve accessibility of palaeopathological data. Papers from the Institute of Archaeology, 29(1), 1-10.

Fiorenza, L., Yong, R., Ranjitkar, S., Hughes, S., Quayle, M., McMenamin, P. G., Kaidonis, J., Townsend, G. C., \& Adams, J. W. (2018). Technical note: The use of 3D printing in dental anthropology collections. American Journal of Physical Anthropology, 167(2), 400-406. https://doi.org/10.1002/ajpa.23640

Freiwald, C., \& Miller Wolf, K. A. (2019). Considering Conservation of Human Skeletal Remains in Archaeological Contexts. Advances in Archaeological Practice, 7 (1), 3-9.

Fronza, V. (2001). Il sistema degli archivi nella gestione di un cantiere di scavo e la sua integrazione in un sistema globale (l'esperienza senese). Workshop Soluzioni GIS nell'informatizzazione dello scavo archeologico (Siena, 9 giugno 2001), 25-34

Giannini, C. (2010). Dizionario del restauro. Tecniche, diagnostica, conservazione, Firenze.

Goldstein, L.G. (1976). Spatial Structure and Social Organization: Regional Manifestations of Mississippian Society, Unpublished Ph.D. Dissertation, Northwestern University.

ICOM Code of Ethics for Museums. (2009).

ICOM Terminology to characterize the conservation of tangible cultural heritage (2010).

Karadimas, N., Kotsopoulos, K., Papastamatiou, N., Spyropoulos, A., \& Tsergoulas, K. (2010). Combination of Cost Effective 3D scanning techniques for the development of web virtual museums, Conference: ICCOM'10 Proceedings of the 14th WSEAS International Conference on Communications (Corfu Island, Greece - July 2010). https://doi.org/10.13140/2.1.4102.9443

Knüsel, C.J. (2010). Bioarchaeology: a synthetic approach. Bull. Mém. Soc. Anthropol. Paris, 22, $62-73$. https://doi.org/10.1007/s13219-010-0003-1

Korneliussen, T. S., Albrechtsen A., \& Nielsen R., (2014). ANGSD: Analysis of Next Generation Sequencing Data. BMC Bioinformatics, 15, 356. https://doi.org/10.1186/s12859-014-0356-4

Kotulanová, K., Chalás, I., \& Urbanová, P. (2014). 3D Virtual Model Database of Human Faces: Applications in Anthropology and Forensic Sciences. Dolní Věstonice Studies, 20 (Mikulov Conference Anthropology Meeting 2014), 177-180.

Lari, M., Di Vincenzo, F., Borsato, A., Ghirotto, S., Micheli, M., Balsamo, C., Collina, C., De Bellis, G., Frisia, S., Giacobini, G., Gigli, E., Hellstrom, J.C., Lannino, A., Modi, A., Pietrelli, A., Pilli, E., Profico, A., Ramirez, O., Rizzi, E., Vai, S., Venturo, D., Piperno, M., Lalueza-Fox, C., Barbujani, G., Caramelli, D., \& Manzi, G. (2015). The Neanderthal in the karst: first dating, morphometric, and paleogenetic data on the fossil skeleton from Altamura (Italy). Journal of Human Evolution, 82, 88-94. https://doi.org/10.1016/j.jhevol.2015.02.007

Larsen, C.S. (2017). Bioarchaeology in perspective: from classifications of the dead to conditions of the living. American Journal of Physical Anthropology, 165, 865-878. https://doi.org/10.1002/ajpa.23322

Larson, L.H. Jr. (1971). Archaeological implications of social stratification at the Etowah Site, Georgia, in J.A. Brown (Ed.), Approaches to the Social Dimensions of Mortuary Practices, «Am. Antiquit.», 36 (pp. 58-67).

Lee, W. J., Yoon, A. Y., Song, M. K., Wilkinson, C. M., \& Shin, D. H. (2014). The archaeological contribution of forensic craniofacial reconstruction to a portrait drawing of a Korean historical figure. Journal of Archaeological Science, 49, 228-236. https://doi.org/10.1016/j.jas.2014.05.022

Manacorda, D. (2014). L'Italia agli italiani. Istruzioni ed ostruzioni per il patrimonio culturale, Bari.

Mandarano, N. (2019), Musei e media digitali, Roma.

Marquardt, W. H., Montet-White A., \& Scholtz, S. C. (1982). Resolving the Crisis in Archaeological Collections Curation. American Antiquity, 47(2), 409-418. https://doi.org/10.1017/S0002731600061308

Matè, D., Adamo, M., Cotellessa, G., De Francesco, M., \& Trematerra, P. (2016). Azione dei Blattoidei su "stampe a colori": fotografiche, fotomeccaniche e digitali, Poster Sessione XI - Entomologia merceologica e urbana (Merceologica), Atti XXV Congresso Nazionale Italiano di Entomologia (Padova, 24-25 giugno 2016), 344.

McGimsey, C. R. (1972). Public Archaeology, New York.

Mc Gowan, G.S., \& LaRoche C.J. (1996). The Ethical Dilemma Facing Conservation: Care and Treatment of Human Skeletal Remains and Mortuary Objects. Journal of the American Institute for Conservation, 35/2, 109-121. https://doi.org/10.1179/019713696806124548

Michalski, S., \& Pedersoli, J. L. (2016). The ABC Method: a risk management approach to the preservation of cultural heritage, Ottawa.

Monza, F. (2014). Esporre I resti umani: un problema tra ricerca, etica e comunicazione. II caso britannico. Museologica Scientifica Memorie, 11, 241-244. 
Monza, F. (2015). Un approccio multidisciplinare alla gestione dei resti umani nei musei, Poster XXI Congresso degli Antropologi Italiani (Bologna/Ravenna, 3-5 settembre 2015).

Moshenska, G. (2017). Key Concepts in Public Archaeology, London.

Nagar, Y. (2011). Human osteological database at the Israel Antiquities Authority Overview and some examples of use. Bioarchaeology of the Near East, 5, 1-18.

Nielsen, R., Paul, J. S., Albrechtsen A., \& Song Y. S. (2011). Genotype and SNP calling from next-generation sequencing data. Nat Rev Genet, 12(6), 443-451. https://doi.org/10.1038/nrg2986

Pedersoli, J. L., Altomarchi, C., \& Michalski, S. (2016). A Guide to Risk Management of Cultural Heritage, Ottawa.

Peebles, C.S. (1971). Moundville and surrounding sites: Some structural considerations of mortuary practices, in J.A. Brown (Ed.), Approaches to the Social Dimensions of Mortuary Practices, Am. Antiquit., 36 (pp. 68-91). https://doi.org/10.1017/S0081130000002550

Perry, M.A. (2007). Is bioarchaeology a handmaiden to history? Developing a historical bioarchaeology. Journal of Anthropological Archaeology, 26, 486-515. https://doi.org/10.1016/j.jaa.2007.02.002

Petarosa, A., Garvinc, H. M., Sholtse, S. B., Schlagerf, S., Sebastian, K.T.S., \& Wärmländer, S. K. T. S. (2017). Sexual dimorphism and regional variation in human frontal bone inclination measured via digital 3D models. Legal Medicine, 29, 53-61. http://dx.doi.org/10.1016/j.legalmed.2017.10.001

Polly, P. D., \& Stringer, C. (2011). The Ancient Human Occupation of Britain (AHOB) Database, in R. Macchiarelli, G. C. Weninger (eds.) Pleistocene Databases: Acquisition, Storing, Sharing, Mettmann (pp. 51-60).

Redfern, R., \& Bekvalac, J. (2013). The Museum of London: An Overview of Policies and Practice, in M. Giesen (Ed.

Curating Human Remains. Caring for the Dead in the United Kingdom, Newcastle University, (pp. 87-98).

Rmoutilová, R., Guyomarc'h, P., Velemínský, P., Šefčáková, A., Samsel, M., Santos, F., Maureille, B., \& Brůžek, J. (2018). Virtual reconstruction of the Upper Palaeolithic skull from ZlatyÂ Kůn̆, Czech Republic: Sex assessment and morphological affinity. PLoS ONE 13(8): e0201431. https://doi.org/10.1371/journal.Pone.0201431

Rose, J.C., Green, T.J., \& Green, V.D. (1996). Nagpra is forever: Osteology and the Repatriation of Skeletons. Annual Review of Anthropology, 25, 81-103.

Rothschild, N.A. (1975). Age and Sex, Status and Role, in Prehistoric Societies of Eastern North America, Ph.D. Dissertation, University of New York.

Ruda, A. (2016). Exploring Tourism Possibilities Using GIS-based Spatial Association Methods. Geographia Technica, 11(2), 87-101. https://doi: 10.21163/GT_2016.112.09

Samadelli, M., Zink, A., Roselli, G., Gabrielli, S., Tabandeh, S., \& Fernicola, C. (2019). Development of passive controlled atmosphere display cases for the conservation of cultural assets. Journal of Cultural Heritage, 35, 145-153. https://doi.org/10.1016/j.culher.2018.05.005

Saxe, A.A. (1970). Social Dimensions of Mortuary Practices, Ph.D. Dissertation, University of Michigan.

Seguchi, N., \& Dudzik, B. (2019). 3D Data Acquisition for Bioarchaeology, Forensic Anthropology and Archaeology. Cambridge, Massachusetts: Academic Press. https://doi.org/10.1016/C2017-0-02320-0

Serrano, A., Jiménez Arenas, J. M., \& Esquivel, J. A. (2016). Evolución humana y antropología virtual: una propuesta para la docencia y la investigación. Revista Otarq Otras arqueologías, 1, $267-283$. http://dx.doi.org/10.23914/otarq.v0i1.98

Skeates, R., McDavid, C., \& Carman, J. (Eds.) (2012). The Oxford Handbook of Public Archaeology, Oxford.

Šlaus, M., Petaros, A., \& Adamić, A. (2015). Bioarchaeology. A discipline that encompasses the past, present and future of mankind. Periodicum Biologorum, 117/1, 27-34. https://hrcak.srce.hr/139483

Stull, K. E., Tise, M. L., , Ali, Z., \& Fowler, D. L. (2014). Accuracy and reliability of measurements obtained from computed tomography 3D volume rendered images. Forensic Science International, 238, $133-140$. https://doi.org/10.1016/j.forsciint.2014.03.005

Suppersberger Hamre, S., Ersland, G. A., Daux, V., Parson, W., \& Wilkinson, C. (2017). Three individuals, three stories, three burials from medieval Trondheim, Norway. PLoS ONE 12(7), 1-26. https://doi.org/10.1371/journal.pone.0180277

Tainter, J.A. (1978). Mortuary practices and the study of prehistoric social systems, in M. Schiffer (Ed.), Archaeological Advances in Method and Theory, 1 (pp. 105-141).

Thanaphattarapornchai, M. (2012). Close-Range Photogrammetry for 3D Archaeological Documentation: Digital Human Remains, Poster Finearts Department, Thailand 2012.

Turner, T.R. (Ed.) (2005). Biological Anthropology and Ethics: From Repatriation to Genetic Identity, New York. 
Turner, T.R., Wagner, J.K., \& Cabana, G.S. (2018). Ethics in biological anthropology. American Journal of Physical Anthropology, 165, 939-951. https://doi.org/10.1002/ajpa.23367

Ubelaker, D.H., \& Guttenplan Grant. L., (1989). Human Skeletal Remains: Preservation or Reburial ?. Yearbook of Physical Anthropology, 32, 249-287.

UNI 10829 (1999). Works of art of historical importance - Ambient conditions or the conservation - Measurement and analysis.

UNI EN 15757 (2010). Conservation of Cultural Property - Specifications for temperature and relative humidity to limit climate-induced mechanical damage in organic hygroscopic materials.

Urbanová, P., Hejna, P., \& Jurda, M. (2015).Three-dimensional Body Surface Documentation in Forensic Pathology, Poster Conference: AAFS 67th Annual Scientific Meeting, Florida USA.

Valenti, M. (1998). La gestione informatica del dato; percorsi ed evoluzioni nell'attività della cattedra di Archeologia Medievale del Dipartimento di Archeologia e Storia delle Arti-Sezione Archeologica dell'Università di Siena. Archeologia e Calcolatori, 9, 305-329.

Valenti, M. (2017). Appunti, grezzi, per un'agenda di Archeologia Pubblica in Italia, in J. Moreland, J. Mitchell, B. Leal (eds.) Encounters, Excavations and Argosies: Essays for Richard Hodges, Oxford (pp. 314-328).

Volpe, G. (2019). Il bene nostro. Un impegno per il patrimonio culturale, Bari.

Volpe, G. (2020). Archeologia Pubblica. Metodi, tecniche, esperienze, Roma.

White, T.D., Falkens, P.A. (Eds.). (2005). The Human Bone manual, USA.

Wrobel, G.D., Biggs, J.A., \& Hair, A.L. (2019). Digital Modeling for Bioarchaeologists. Advances in Archaeological Practice, 7, 47-54. https://doi.org/10.1017/aap.2018.47

Zechini, M. E., Holmstrom, J., Voas, M., \& Killgrove, K. (2016). Digitizing ROGeR: Creating a Recommended Osteology Guide for e-Readers, Poster University of Florida 2016. 